\title{
Prevalence and associated risk factors of anemia among HIV infected children attending Gondar university hospital, Northwest Ethiopia: a cross sectional study
}

Bamlaku Enawgaw ${ }^{1 *}$, Meseret Alem², Mulugeta Melku', Zelalem Addis ${ }^{3}$, Betelihem Terefe ${ }^{1}$ and Gashaw Yitayew ${ }^{4}$

\begin{abstract}
Background: Anemia is the most common hematological abnormalities in HIV patients and it is a wide spread public health problem. The World Health Organization estimates that over 2 billion people are anemic worldwide with more than 100 million of these anemic children living in Africa. In Ethiopia, there is limited information about the prevalence and factors associated with anemia among HIV positive children. Thus, this study aimed to determine the prevalence and associated factors of anemia among HIV infected children aged 6 months to 14 years in Gondar university Hospital antiretroviral treatment clinic.
\end{abstract}

Methods: A cross-sectional study was conducted on 265 HIV infected children from February to June 2013 on HIV infected children attending Gondar university Hospital ART clinic. The study subjects were selected with systematic random sampling technique. Data of socio demographic characteristics and clinical conditions of the study subjects was collected using a structured pretested questionnaire. Hemoglobin value and CD4 counts were determined by cell Dyne 1800 and FACS count machine respectively. WHO Cut off value of hemoglobin was taken and adjusted to altitude to define anemia. Data was analyzed by using the SPSS version 20 statistical software and bivariate and multivariate logistic regression was used to identify predictors.

Results: Anemia was present in $16.2 \%$ (43/265) of children, $60.5 \%$ of them had mild anemia, $37.2 \%$ had moderate anemia and $2.3 \%$ had severe anemia. About $46.5 \%$ of anemic children had normocytic-normochromic anemia followed by macrocytic-normochromic anemia (39.5\%). In this study, anemia was associated with eating green leafy vegetables $(\mathrm{OR}=0.43,95 \% \mathrm{Cl}(0.188-0.981)$ and being on cotrimoxazole treatment $(\mathrm{OR}=2.169,95 \% \mathrm{Cl}$ (1.047-4.49). But there was no significant association with age, sex, WHO clinical stage, opportunistic infections, intestinal parasitic infection and CD4 count percentage.

Conclusions: The majority of HIV positive children in Northwest Ethiopia have a mild type of anemia and the increase in prevalence of anemia is due to being on cotrimoxazole and eating green leafy vegetables. Therefore, early diagnosis and treatment of anemia is essential in these patients.

Keywords: Anemia, HIV, Risk factors, Children

\footnotetext{
* Correspondence: bamlak21@gmail.com

'Department of Hematology \& Immunohematology, School of Biomedical and Laboratory Sciences, College of Medicine and Health Sciences, University of Gondar, P.O. Box 196, Gondar, Ethiopia

Full list of author information is available at the end of the article
}

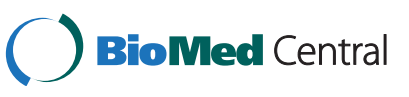

(c) 2015 Enawgaw et al. Open Access This article is distributed under the terms of the Creative Commons Attribution 4.0 International License (http://creativecommons.org/licenses/by/4.0/), which permits unrestricted use, distribution, and reproduction in any medium, provided you give appropriate credit to the original author(s) and the source, provide a link to the Creative Commons license, and indicate if changes were made. The Creative Commons Public Domain Dedication waiver (http://creativecommons.org/publicdomain/zero/1.0/) applies to the data made available in this article, unless otherwise stated. 


\section{Background}

Of HIV related hematological abnormalities, anemia is the most common hematological complication of HIV infection that has a significant impact on the quality of life and clinical outcomes [1]. Of patients, it is estimated that up to $90 \%$ of adults and children develop anemia during HIV infection [2]. According to World Health Organization (WHO) definitions, anemia is defined as hemoglobin level less than $11 \mathrm{~g} / \mathrm{dl}$ for children $<5$ years old, $<11.5 \mathrm{~g} / \mathrm{dl}$ for children 5-11.9 years old and $<12 \mathrm{~g} / \mathrm{dl}$ for children 12-14.9 years old after altitude adjustment [3-5]. Anemia is also classified as mild degree (Hgb 10.0-10.9 g/dl), moderate (Hgb 7.0-9.9 g/dl), severe (Hgb 4.0-7.0 g/dl), and very severe $\mathrm{Hgb}$ less than $4.0 \mathrm{~g} / \mathrm{dl}$. It can also be classified based on the Hematocrit (PCV) percent. Packed cell volume (PCV) of less than $33.0 \%$ is regarded as anemia by the World Health Organization [3, 6, 7].

Anemia has been shown to be a significant predictor of progression to AIDS and several studies have shown that as hemoglobin levels decrease, the risk of HIV disease progression increases [8] and it is associated with an increased risk of death in both children and adult patients [1,9-11]. It is a wide spread public health problem; The WHO estimates that over 2 billion people are anemic worldwide with more than 100 million of these anemic children living in Africa [12]. In East Africa, the prevalence of anemia ranges from 15-93 \% [13]. According to the 2011 Ethiopia Demographic and Health Survey more than four in ten children (44\%) are anemic. One child of every five (21\%) has mild anemia, another $20 \%$ have moderate anemia, and $3 \%$ have severe anemia in the country [14]. But there is limited information about prevalence of anemia among HIV infected children in Ethiopia.

Anemia prevalence in children with HIV depends on several factors, such as stage of HIV infection, sex, age, race, and concurrent illness as well as the definition of anemia used. In general, as the HIV disease progresses, the prevalence and severity of anemia increases [9]. The high prevalence of anemia in HIV infected children in developing countries may be attributed to the fact that many of the children in these regions are also iron deficient which is compounded by poor socioeconomic status $[15,16]$.

In addition to the direct effect of HIV, highly active antiretroviral therapy (HAART) also causes anemia. Although HAART has the capability of reducing the incidence of anemia [17] and lymphopenia by suppressing viral replication and increases CD4 cell count, anemia remains a common problem even for patients treated with antiretroviral agents. Anemia due to drugs, such as cotrimoxazole, pentamidine, foscarnet and zidovudine (AZT) often reflects reticuloendothelial iron block. Among the antiretroviral drugs, AZT is the most widely used drug that results in myelosuppression and thus anemia [18-21].

In Ethiopia, there is limited information about the prevalence and factors associated with anemia among HIV positive children. The study conducted in Jimma [18] is not enough to give conclusions to the general population. Since the normal hematological values are different in children on HAART and HAART naive, it is difficult to drive conclusions because the study conducted in Jimma only took those children who were on HAART. Therefore the current study determined the prevalence and associated factors of anemia among HIV infected children, aged 6 months to 14 years, in Gondar university Hospital ART Clinic.

\section{Methods}

\section{Study setting and population}

An institutional based, cross-sectional study was conducted from February to June, 2013 among 265 HIV infected children, aged 6 months to 14 years, attending Gondar university hospital. At the time of data collection there were 722 HIV infected children attending Gondar university hospital ART clinic. From them 265 were selected using systematic random sampling technique. A detailed history including, the socio-demographic characteristics, presenting symptoms, presence of symptoms related to anemia, nutritional history, past medical history, previous and current drug history, caretaker characteristics (including education level, occupation and income) was assessed with a pre-tested and a standardized questionnaire. All study subjects were approached during their respective appointments for follow up. After the interview, a detailed review of the medical records, such as concurrent opportunistic infections and WHO clinical staging of HIV disease was recorded. Then blood samples for hemoglobin determination and CD4 counts and stool samples for intestinal parasite were collected and processed.

\section{Laboratory analysis}

About $4 \mathrm{ml}$ of venous blood was collected by an experienced laboratory technologist from each subject for $\mathrm{CD} 4$ count and hematological parameters analysis. Hematological parameters; hemoglobin (Hgb), hematocrit (\%), mean cell volume (MCV), mean cell hemoglobin $(\mathrm{MCH})$, mean cell hemoglobin concentration $(\mathrm{MCHC})$, red blood cell count (RBC) and red cell distribution width (RDW) were determined using the automated blood analyzer Cell-Dyne 1800 and CD4 count was assayed using the Becton Dickenson (BD) FACS caliber. For intestinal parasite examination a stool sample was collected and a drop of saline was mixed by an applicator stick on the slide and was examined for intestinal parasites by experienced laboratory technologist. 


\section{Statistical analysis}

The data was cleaned, edited, checked for completeness and entered in to the data program SPSS version 20 statistical software for analysis. Descriptive statistics were used to give a clear picture of dependent and independent variables. Bivariate and multivariate logistic regression was used to identify predictors.

\section{Ethical clearance}

The study was conducted after ethical letters were obtained from university of Gondar Ethical Committee. Informed written consent was taken from the caretakers and in addition assent was obtained from older children (above 8 years) before enrollment in the study. Then the objective of this research was explained to the study participant's, and those willing to participate were included. Participation in the study was voluntary and refusal was possible. To ensure confidentiality of data, study subjects were identified using codes and unauthorized persons were not able to access the collected data. The study participants' result were reported to the physician for proper management.

\section{Results}

\section{Socio-demographic and clinical characteristics of study} participants

A total of 264 HIV positive children, aged between 6 months and 14 years old, participated in the study. One hundred thirty four were males and one hundred thirty one were females, M:F was almost 1:1 (50.6 and $49.4 \%$ respectively). The mean age of the study participants was $9.3 \pm 3.3$ years. The biggest percentage (61.9\%) of children were aged 5 to 11.9 years. About $48.7 \%$ were receiving cotrimoxazole prophylaxis and $70.9 \%$ were on antiretroviral therapy (Table 1).

\section{Prevalence of anemia}

The prevalence of anemia among the study children was obtained by considering the cut off values of $\mathrm{Hgb}$ ( $<11 \mathrm{~g} / \mathrm{dl}$ for children $<5$ years old, $<11.5 \mathrm{~g} / \mathrm{dl}$ for children 5-11.9 years old and $<12 \mathrm{~g} / \mathrm{dl}$ for children $12-14.9$ years old) after altitude adjustments. The study area has an altitude of $2133 \mathrm{~m}$ and $\mathrm{Hgb}$ value was adjusted by subtracting $0.08 \mathrm{~g} / \mathrm{dl}$ [3]). Based on this, prevalence of anemia was $16.2 \%$ (43/265). From the anemic children, $60.5 \%$ of them had mild anemia, $37.2 \%$ had moderate anemia and $2.3 \%$ had severe anemia. Regarding the type of anemia, about $46.5 \%$ of anemic children had normocytic-normochromic anemia followed by macrocytic-normochromic anemia (39.5 \%) (Fig. 1).

To determine risk factors of anemia among HIV infected children, the bivariate and multivariate logistic regression was used to identify predictors. Based on this, anemia was associated with eating green leafy vegetables
Table 1 Characteristics of HIV positive children attending Gondar university hospital ART clinic from February to June, 2013, Northwest Ethiopia

\begin{tabular}{|c|c|c|c|}
\hline Characteristics & & Frequency & Percentage \\
\hline \multirow[t]{3}{*}{ Age in years } & $0.5-4.9$ & 24 & 9.1 \\
\hline & $5-11.9$ & 163 & 61.5 \\
\hline & $12-14.9$ & 78 & 29.4 \\
\hline \multirow[t]{2}{*}{ Sex } & Male & 134 & 50.6 \\
\hline & Female & 131 & 49.4 \\
\hline \multirow[t]{2}{*}{ Residence } & Urban & 250 & 94.3 \\
\hline & Rural & 15 & 5.7 \\
\hline \multirow[t]{3}{*}{ Religion of guardian } & Orthodox & 233 & 87.92 \\
\hline & Muslim & 29 & 10.94 \\
\hline & Protestant & 3 & 1.13 \\
\hline \multirow{5}{*}{$\begin{array}{l}\text { Occupation of } \\
\text { guardian }\end{array}$} & Merchant & 47 & 17.7 \\
\hline & Farmer & 23 & 8.7 \\
\hline & Government employed & 49 & 18.5 \\
\hline & Non-employed & 33 & 12.5 \\
\hline & Daily laborer & 113 & 42.6 \\
\hline \multirow{4}{*}{$\begin{array}{l}\text { Educational status } \\
\text { of guardian }\end{array}$} & Illiterate & 78 & 29.4 \\
\hline & Elementary School & 97 & 36.6 \\
\hline & High School & 63 & 23.8 \\
\hline & Certificate and above & 27 & 10.2 \\
\hline \multirow{2}{*}{$\begin{array}{l}\text { Meat and animal } \\
\text { products intake }\end{array}$} & Yes & 199 & 75.1 \\
\hline & No & 66 & 24.9 \\
\hline \multirow{2}{*}{$\begin{array}{l}\text { Green leafy } \\
\text { vegetables intake }\end{array}$} & Yes & 219 & 82.6 \\
\hline & No & 46 & 17.4 \\
\hline \multirow[t]{4}{*}{ WHO stage } & । & 63 & 23.8 \\
\hline & $\|$ & 72 & 27.2 \\
\hline & III & 105 & 39.6 \\
\hline & IV & 25 & 9.4 \\
\hline \multirow[t]{2}{*}{ HAART } & Yes & 188 & 70.9 \\
\hline & No & 77 & 29.1 \\
\hline \multirow{2}{*}{$\begin{array}{l}\text { Opportunistic } \\
\text { infections }\end{array}$} & Yes & 19 & 7.2 \\
\hline & No & 246 & 92.8 \\
\hline \multirow[t]{2}{*}{ Cotrimoxazole } & Yes & 129 & 48.7 \\
\hline & No & 136 & 51.3 \\
\hline
\end{tabular}

and taking cotrimoxazole treatment. But there was no significant association between anemia and sociodemographic characteristics, CD4 count, WHO clinical stage, parasitic infections and OPIs (Table 2).

\section{Discussion}

Anemia is a frequently encountered aberration in HIV patients [22] which may be clinically important. Multifactorial 


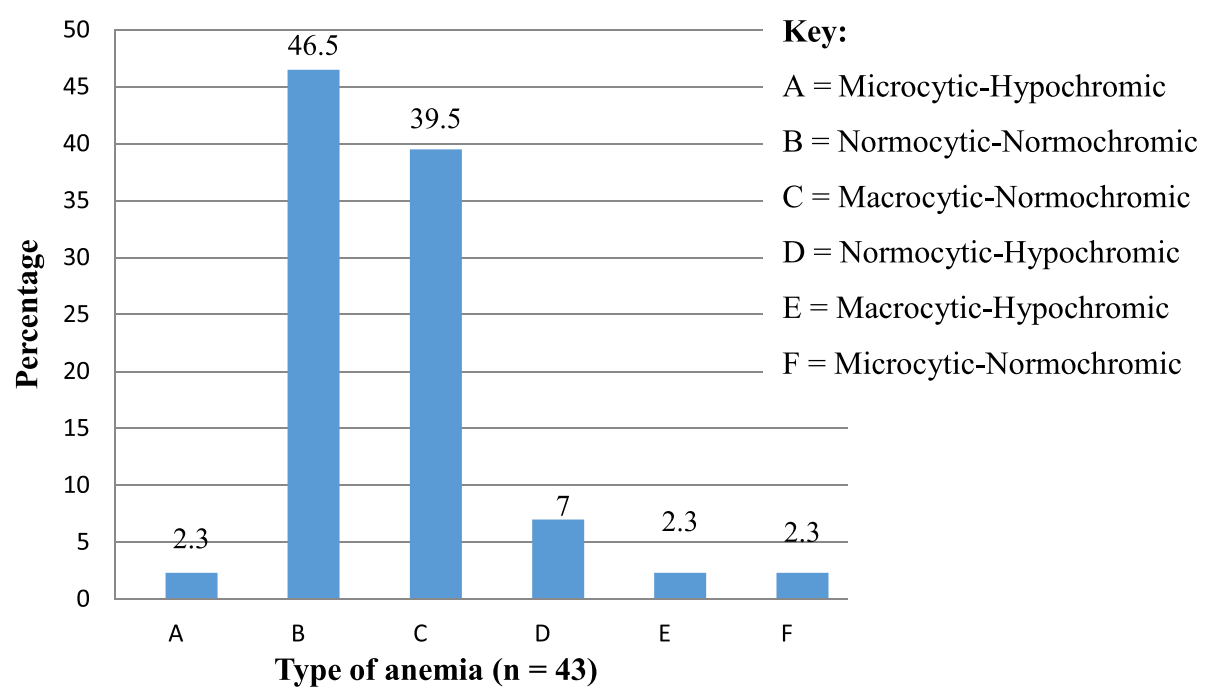

Fig. 1 Type of anemia among HIV positive children attending Gondar University Hospital ART Clinic from February - June, 2013, Northwest Ethiopia

Table 2 Association of socio-demographic and other clinical variables with anemia among HIV infected children attending Gondar university Hospital ART clinic from February - June, 2013

\begin{tabular}{|c|c|c|c|c|c|}
\hline Variables & & Anemic & Non-anemic & COR $(95 \% \mathrm{Cl})$ & AOR $(95 \% \mathrm{Cl})$ \\
\hline \multirow[t]{3}{*}{$\overline{\text { Age }}$} & $0.5-5$ years & $4(16.7 \%)$ & $20(83.3 \%)$ & $1(0.293-3.413)$ & $1.388(0.359-5.363)$ \\
\hline & 5-11years & $26(16.0 \%)$ & $137(84.0 \%)$ & $1.054(0.509-2.183)$ & $1.285(0.590-2.7980)$ \\
\hline & 11-14years & $13(16.7 \%)$ & $65(83.3 \%)$ & $1^{\mathrm{a}}$ & $1^{a}$ \\
\hline \multirow[t]{2}{*}{ Sex } & Male & $20(14.9 \%)$ & $114(85.1 \%)$ & $1^{a}$ & $1^{\mathrm{a}}$ \\
\hline & Female & $23(17.6 \%)$ & $108(82.4 \%)$ & $0.824(0.428-1.585)$ & $0.741(0.358-1.530)$ \\
\hline \multirow[t]{2}{*}{ Eating animal products } & Yes & $28(14.1 \%)$ & $171(85.9 \%)$ & $1^{a}$ & \\
\hline & No & $15(22.7 \%)$ & $51(77.3 \%)$ & $0.557(0.276-1.122)$ & \\
\hline \multirow[t]{2}{*}{ Eating green leafy vegetable } & Yes & $31(14.2 \%)$ & $188(85.8 \%)$ & $1^{a}$ & $1^{a}$ \\
\hline & No & $12(26.1 \%)$ & 34 (73.9 \%) & $0.467(0.219-0.999)$ & $0.430(0.188-0.981)$ \\
\hline \multirow[t]{4}{*}{ WHO Clinical stage } & । & $15(23.8 \%)$ & $48(76.2 \%)$ & $1^{\mathrm{a}}$ & $1^{\mathrm{a}}$ \\
\hline & $\|$ & $11(15.3 \%)$ & $61(84.7 \%)$ & $1.733(0.73-4.116)$ & $1.886(0.758-4.689)$ \\
\hline & III & $16(15.2 \%)$ & 89 (84.8 \%) & $1.738(0.791-3.819)$ & $1.497(0.557-4.022)$ \\
\hline & IV & $1(4.0 \%)$ & $24(96.0 \%)$ & $7.5(0.934-60.196)$ & $4.806(0.547-42.203)$ \\
\hline \multirow[t]{2}{*}{ HAART } & Yes & $24(12.8 \%)$ & $164(87.2 \%)$ & $1^{\mathrm{a}}$ & $1^{a}$ \\
\hline & No & $19(24.7 \%)$ & $58(75.3 \%)$ & $0.447(0.228-0.875)$ & $0.671(0.272-1.652)$ \\
\hline \multirow[t]{2}{*}{ Opportunistic infections } & Yes & $6(31.6 \%)$ & $13(68.4 \%)$ & $0.384(0.137-1.073)$ & $0.416(0.131-1.319)$ \\
\hline & No & $37(15.0 \%)$ & $209(85.0 \%)$ & $1^{a}$ & $1^{\mathrm{a}}$ \\
\hline \multirow[t]{2}{*}{ Cotrimoxazole } & Yes & $27(20.9 \%)$ & $102(79.1 \%)$ & $1^{a}$ & $1^{\mathrm{a}}$ \\
\hline & No & $16(11.8 \%)$ & $120(88.2 \%)$ & $1.985(1.014-3.889)$ & $2.169(1.047-4.490)$ \\
\hline \multirow[t]{2}{*}{ Intestinal parasite infection } & Yes & $10(15.4 \%)$ & 55 (84.6\%) & $1.087(0.503-2.348)$ & $0.841(0.373-1.895)$ \\
\hline & No & $33(16.5 \%)$ & $167(83.5 \%)$ & $1^{a}$ & $1^{a}$ \\
\hline \multirow[t]{3}{*}{ CD4 percentage } & $<15 \%$ & $9(18.8 \%)$ & 39 (81.2 \%) & $0.744(0.306-1.81)$ & $0.956(0.341-2.686)$ \\
\hline & $15-25 \%$ & $17(16.8 \%)$ & 84 (83.2 \%) & $0.848(0.408-1.765)$ & $1.022(0.455-2.293)$ \\
\hline & $>25 \%$ & $17(14.7 \%)$ & 99 (85.3\%) & $1^{a}$ & $1^{\mathrm{a}}$ \\
\hline
\end{tabular}

${ }^{a}$ Reference category, bold numeric indicates statistically significant association 
causes of anemia may complicate its original cause and/or its suitable treatment [23]. The pathogenesis of anemia in HIV infection is multifactorial which includes bleeding (gastrointestinal malignancy/severe infection), insufficient dietary intake (vitamins such as cobalamin and folate, iron, and general malnutrition), hemolytic anemia (i.e., malignancies, infections, splenomegaly, and immune dysfunction) and changes in erythropoietin synthesis and/or bone marrow suppression [2].

The prevalence of anemia in this study was $43 / 265$ $(16.2 \%)$. This is lower than the reports of studies done in India [24], Cape Town [25], Uganda [11], Tanzania [26] and Jimma [18] which were 66, 73, 91.7, 21.9 and $44 \%$, respectively. On the other hand, it is higher than the study done in Northwest Brazil $13.6 \%$ [27]. This difference may be due to differences in ethnicity, geographical location, study designs and time of study. Also there are age differences in the study participants, some took up to 12 years old children, some up to 10 years old children but the current study took children up to 14 years old.

In this study from anemic children, $60.5 \%$ of them had mild anemia, $37.2 \%$ moderate anemia and $2.3 \%$ had severe anemia which is comparable with the study done in Uganda in 2002 [11] where they reported $35.1 \%$ prevalence of moderate to severe anemia and from 2007 to 2009 [28] which showed $62.2 \%$ patients had mild anemia and $32.0 \%$ had moderate anemia while $4.8 \%$ had severe anemia. In contrast, prevalence of severe life threatening anemia in our study, which was $2.3 \%$, was lower than study done in Jimma, which was $14.3 \%$ [18].

In the current study about $46.5 \%$ of anemic children had normocytic-normochromic anemia followed by macrocytic-normochromic anemia (39.5\%). But in Uganda [28] from 2007 to 2009 the predominant type of anemia was microcytic-hypochromic anemia (44.9\%) followed by normocytic-hypochromic anemia (26.5\%) and normocytic-normochromic anemia (19.0\%).

In this study, anemia was associated with eating green leafy vegetables and being on cotrimoxazole treatment. But there is no significant association with age, sex, residence, WHO clinical stage, HAART, opportunistic infections, intestinal parasitic infection and CD4 percentage. But in contradiction to this study, a study done in Tanzania showed that not being on HAART, having CD4 \% $<25 \%$, having a history of tuberculosis and having hookworm infestation, were independent risk factors for anemia [26]. A similar study on children aged 1 to 12 years in India, showed that age younger than 6 years old, rural residence, advanced HIV disease stage and TB infection were risk factors for anemia while HAART was protective while gender, cotrimoxazole and HAART regimen type had no association with anemia [24].

\section{Conclusion}

Our findings showed that majority of HIV positive children in Northwest Ethiopia who are anemic have mild anemia and the prevalence of anemia is related to being on cotrimoxazole and eating leafy vegetables. Therefore, early diagnosis and treatment of anemia is essential in these patients. In this study direct wet mount was used for parasitic examination and this may less sensitive to detect ova of parasites. Also longitudinal studies on iron, folate, cobalamin levels and bone marrow examination, erythropoietin and viral load determination, are needed to determine the actual etiology of anemia in HIV infected children.

\section{Abbreviations}

AIDS: Acquired immune deficiency syndrome; ART: Antiretroviral treatment; AZT: Zidovudine; CBC: Complete blood count; $C D 4^{+}$: Cluster differentiation 4; FACS: Florescence activated cell sorting; HAART: Highly active antiretroviral treatment; Hgb: Hemoglobin; HIV: Human immunodeficiency virus; MCH: Mean cell haemoglobin; MCHC: Mean cell haemoglobin concentration; MCV: Mean cell haemoglobin; OPI: Opportunistic infections; PCV: Packed cell volume; RDW: Red cell distribution width; TB: Tuberculosis; WHO: World Health Organization.

\section{Competing interests}

The authors declare that they have no competing interests.

\section{Authors' contributions}

BE: Recruited the patients, collected and analyzed the data and wrote the draft of the manuscript. MA: Conceived the study, obtained ethics papers, supervised the collection of data and revised the draft. MM: Interpreted the collected data and wrote the draft along with BE. ZA: Ensured quality of the laboratory results and revised the draft of the manuscript. BT: Involve in proposal development, data collection and entry for analysis. GY: Perform laboratory tests and summarize the result. All authors read and approved the final version of the manuscript.

\section{Acknowledgements}

The authors would like to extend their appreciation to Gondar university hospital ART laboratory professionals for their help in the collection, processing and analyzing of laboratory tests and university of Gondar for the financial support. Also they want to express their great thanks to the study participants for their patience and cooperation.

\section{Author details}

${ }^{1}$ Department of Hematology \& Immunohematology, School of Biomedical and Laboratory Sciences, College of Medicine and Health Sciences, University of Gondar, P.O. Box 196, Gondar, Ethiopia. ${ }^{2}$ Department of Immunology and Molecular Biology, School of Biomedical and Laboratory Sciences, College of Medicine and Health Sciences, University of Gondar, Gondar, Ethiopia.

${ }^{3}$ Department of Medical Microbiology, School of Biomedical and Laboratory Sciences, College of Medicine and Health Sciences, University of Gondar, Gondar, Ethiopia. ${ }^{4}$ Bahir Dar Regional Health Research Laboratory Center, Bahir Dar, Ethiopia.

Received: 3 October 2014 Accepted: 17 September 2015 Published online: 24 September 2015

\section{References}

1. Moore RD. Human immunodeficiency virus infection, anemia and survival. Clin Infect Dis. 1999;29:44-9.

2. Semba RD, Glenda EG. Pathogenesis of anaemia during human immunodeficiency virus infection. J Investig Med. 2001;49(3):225-39.

3. WHO. Haemoglobin concentrations for the diagnosis of anaemia and assessment of severity. Vitamin and mineral nutrition information system. Geneva: World Health Organization; 2011. (WHO/NMH/NHD/MNM/11.1). Available at http://www.who.int/vmnis/indicators/haemoglobin.pdf. 
4. Alemu Y, Atomsa A, Sahlemariam Z. Hematology lecture notes for medical laboratory students. Jimma: Jimma University; 2006.

5. WHO. Haemoglobin concentrations for the diagnosis of anaemia and assessment of severity, WHO Technical report series No 405. Geneva: WHO; 1968.

6. WHO. Preventing and controlling iron deficiency anemia through primary health care. Geneva: WHO; 1989. p. 8.

7. Bruno de Benoist B, McLean E, Egli I, Cogswell M. Worldwide prevalence of anaemia 1993-2005: WHO global database on anaemia. Geneva: WHO; 2008.

8. Volberding PA, Levin AM, Dieterich D. Anemia in HIV infection: clinical impact and evidence-based management strategies. Clin Infect Dis. 2004;38:1454-63.

9. Belperio PS, Rhew DC. Prevalence and outcomes of anaemia in individuals with human immunodefficiency virus: a systemic review of literature. AM J Med. 2004;116:27S-43S

10. Mocroft A, Ole K, Barton SE. Anaemia is an independent predictive marker for clinical prognosis in HIV-infected patients from across Europe. AIDS. 1999;13:943-50

11. Clark TD, Mmiro F, Ndugwa C. Risk factors and cumulative incidence of anaemia among human immunodeficiency virus-infected children in Uganda. Ann Trop Paediatr. 2002;22:11-7.

12. WHO. Focusing on anaemia: towards an integrated approach for effective anaemia control. Geneva: WHO; 2004.

13. De Maeyer E, Adiels-Tegman M. The prevalence of anaemia in the world. World Health Stat Q. 1985;38:302-16.

14. Central Statistical Agency [Ethiopia], ICF International. Ethiopia demographic and health survey 2011. Addis Ababa, Ethiopia and Calverton, Maryland, USA: Central Statistical Agency and ICF International; 2012.

15. Brabin JB, Premji Z, Verhoeff F. Iron deficiency anaemia: reexamining the nature and magnitude of the public health problem. J Nutr. 2001;131:636S-48S.

16. Semba RD. Iron deficiency anemia and the cycle of poverty among human immunodeficiency virus infected women in the inner city. Clin Infect Dis. 2003;37:S105-11.

17. Moore RD, Forney D. Anaemia in HIV-infected patients receiving highly active antiretroviral therapy. J Acquir Immune Defic Syndr. 2002;29(1):54-7.

18. Muluneh A, Fessahaye A. Hematologic abnormalities among children on HAART in Jimma University specialized hospital, Southwestern Ethiopia. Ethiop J Health Sci. 2009;19(2):83-9.

19. Behler C, Shade S, Gregory K, Abrams D, Volberding P. Anemia and HIV in the antiretroviral era: potential significance of testosterone. AIDS Res Hum Retroviruses. 2005;21(3):200-6.

20. Costello C. Haematological abnormalities in human immunodeficiency virus (HIV) disease. J Clin Pathol. 1988:41:711-5.

21. Lim P-L. HIV-related haematological conditions. Singapore: Tan Tock Seng Hospital; 2009.

22. Volberding $P$. The impact of anemia on quality of life in human immunodeficiency virus-infected patients. J Infect Dis. 2002;185:110-4.

23. Kreuzer K-A, Rockstroch JK. Pathogenesis and pathophysiology of anaemia in HIV -infection. Ann Hematol. 1997:75:179-87.

24. Shetn A, Mehta S, Rajagopalan N, Dinakar C, Ramesh E, Samuel NM, et al. Anemia and growth failure among HIV-infected children in India: a retrospective analysis. BMC Pediatr. 2009;9:37.

25. Eley BS, Sive AA, Shuttleworth M. A prospective cross-sectional study of anaemia and peripheral iron status in antiretral naive, HIV-1 infected children in Cape Town, South Africa. BMC Infect Dis. 2002;2:3.

26. Makubi NB, Mugusi F, Magesa MP, Roberts D, Quaresh A. Risk factors for anaemia among HIV infected children attending care and treatment clinic at Muhimbili national hospital in Dar es Salaam, Tanzania. Tanzan J Health Res. 2012;14(1):1-9.

27. Cardoso AM, Scopel KG, Muniz TP, Villamor E, Ferreira UM. Underlying factors associated with anemia in Amazonian children: a population-based cross- sectional study. PLoS ONE. 2012;7(5):e36341.

28. Nyesigire RE, Bajunirwe F, Kiwanuka J. Anaemia in HIV-infected children: severity, types and effect on response to HAART. BMC Pediatr. 2012;12:170

\section{Submit your next manuscript to BioMed Central and take full advantage of:}

- Convenient online submission

- Thorough peer review

- No space constraints or color figure charges

- Immediate publication on acceptance

- Inclusion in PubMed, CAS, Scopus and Google Scholar

- Research which is freely available for redistribution

Submit your manuscript at www.biomedcentral.com/submit 